\title{
A Note on Logistic Mixture Distributions
}

\author{
Satheesh Kumar $\mathrm{C}^{1 *}$ and Manju $\mathrm{L}^{2}$ \\ ${ }^{1}$ Department of Statistics, University of Kerala, India \\ ${ }^{2}$ Department of Community Medicine, Sree Gokulam Medical College, India
}

Submission: May 25, 2017; Published: August 23, 2017

*Corresponding author: Satheesh Kumar C, Department of Statistics, University of Kerala, India; Email: drcsatheeshkumar@gmail.com

\begin{abstract}
Here we consider a wide class of logistic distributions which are obtained by mixing well known type I and type II logistic distributions. We investigate some important properties of the distribution and illustrated the usefulness of the model with the help of a real life dataset.
\end{abstract}

Keywords: Mixture distributions; Model selection; Type I logistic distribution; Type II logistic distribution

\section{Introduction}

The logistic function has wide applications in several areas of research such as demographic studies to estimate the growth of human population [1], as a growth model in biology [2], bioassay problems [3-8], survival data [9], public health [10], income distributions [10] etc. For a detailed account of the properties and applications of the logistic model see Balakrishnan [12]. A continuous random variable $\mathrm{X}$ is said to follow the standard logistic distribution (LD) if its probability density function (PDF) is of the following form.

$$
f_{1}(x)=\frac{e^{-x}}{\left(1+e^{-x}\right)^{2}},
$$

where $x \in R=(-\infty,+\infty)$. The cumulative distribution function (CDF) of the LD is given by

$$
F_{1}(x)=\frac{1}{1+e^{-x}},
$$

For $x \in R$. Balakrishnan and Leung [13] proposed two generalized logistic distributions of type $I\left(L D_{I}\right)$ and $I I\left(L D_{I I}\right)$ respectively through the following PDFs $f_{2}($.$) and f_{3}($.$) , in which$ $x \in R, \alpha>0$ and $\beta>0$.

$$
\begin{aligned}
& f_{2}(x, \alpha)=\alpha \frac{e^{-x}}{\left(1+e^{-x}\right)^{\alpha+1}} \\
& f_{3}(x, \beta)=\frac{\beta e^{-\beta x}}{\left(1+e^{-x}\right)^{\beta+1}}
\end{aligned}
$$

The corresponding CDFs of $L D_{I}$ and $L D_{I I}$ are respectively

$$
F_{2}(x)=\frac{1}{\left(1+e^{-x}\right)^{\alpha}}
$$

and

$$
F_{3}(x)=1-\frac{e^{-\beta x}}{\left(1+e^{-x}\right)^{\beta}} .
$$

If $\mathrm{Z}$ follows $L D_{I}$, then $Y=-Z$ follows $L D_{I I} \cdot L D_{I}$ is negatively skewed for $0<\alpha<1$ and positively skewed for $\alpha>1$. $L D_{I I}$ is positively skewed for $\beta<1$ and negatively skewed for $\beta>1$. Both these classes of distributions have applications in several areas of scientific research. Through this paper we introduce a new class of distributions which is a convex mixture of the $L D_{I}$ and the $L D_{I I}$ and examine its important properties. In section 2, we presented the definition of the proposed class of distributions and obtain some important properties. In section 3 , we illustrate the usefulness of the distribution by utilizing a real life data set.

\section{Mixture of type I and type II logistic distributions}

First we present the definition of the proposed mixture distribution and discuss some of its important properties.

Definition: A continuous random variable $\mathrm{X}$ is said to follow logistic mixture distribution (LMD) if its PDF is of the following form for $x \in R, 0 \leq p \leq 1$, and $\beta>0$.

$$
f(x)=p \alpha \frac{e^{-x}}{\left(1+e^{-x}\right)^{\alpha+1}}+(1-p) \beta \frac{e^{-\beta x}}{\left(1+e^{-x}\right)^{\beta+1}}
$$

A distribution with PDF (7) we denoted by $\operatorname{LMD}(p, \alpha, \beta)$. clearly when $p=1$ the LMD reduces to $L D_{I}$ and when $p=0$ the LMD reduces to $L D_{I I}$. When either $p=1$ and $\alpha=1$ or when $p=0$ and $\beta=1$, the LMD reduces to the LD. The probability plots of the $\operatorname{LMD}(p, \alpha, \beta)$ for particular choices of $P, \alpha$ and $\beta$ are given in Figure 1. 


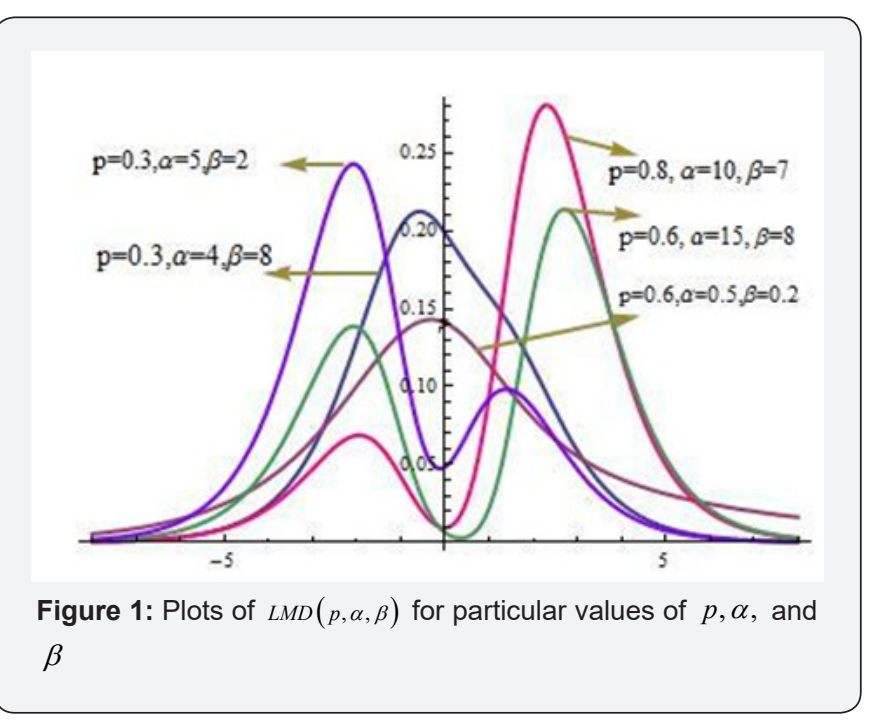

\section{Result 1}

The CDF of $\operatorname{LMD}(p, \alpha, \beta)$, with PDF (7) is the following, for $x \in R$.

$$
F(x)=p \times \frac{1}{\left(1+e^{-x}\right)^{\alpha}}+(1-p) \times\left[1-\frac{e^{-\beta x}}{\left(1+e^{-x}\right)^{\beta}}\right]
$$

The result directly follows from (5) and (6).

Result 2 The characteristic function $\Phi_{X}(t)$ of $\operatorname{LMD}(p, \alpha, \beta)$ with PDF (7) is the following, in which $B(.,$.$) is the complete beta$ function.

$\Phi_{X}(t)=p \alpha \times B(\alpha+i t, 1-i t)+(1-p) \beta \times B(\beta-i t, 1+i t)$,

for $t \in R, \operatorname{Re}(1-i t)>0, \operatorname{Re}(\beta-i t)>0$, and $i=\sqrt{-1}$

Proof: Let X follows $\operatorname{LMD}(p, \alpha, \beta)$ with PDF (7). Then by the definition, the characteristic function of the $\operatorname{LMD}(p, \alpha, \beta)$ is the following, for any $t \in R$, and $i=\sqrt{-1}$.

$$
\begin{aligned}
& \Phi_{X}(t)=\int_{-\infty}^{\infty} e^{i t x} f(x) d x \\
& =p \alpha \int_{-\infty}^{\infty} \frac{e^{(i t-1) x}}{\left(1+e^{-x}\right)^{\alpha+1}} d x+(1-p) \beta \int_{-\infty}^{\infty} \frac{e^{(i t-\beta) x}}{\left(1+e^{-x}\right)^{\beta+1}} d x
\end{aligned}
$$

if we put $u=\frac{1}{1+e^{-x}}$ in $(10)$ we get,

$\Phi_{X}(t)=p \alpha \int_{0}^{1} u^{\alpha+i t-1}(1-u)^{1-i t-1} d u+(1-p) \beta \int_{0}^{1} u^{i t}(1-u)^{\beta-i t-1} d u$

which implies (9), in the light of the beta function. In a similar way we can obtain the moment generating function of the $\operatorname{LMD}(p, \alpha, \beta)$ as given in the following result.

Result 3: The moment generating function of $\operatorname{LMD}(p, \alpha, \beta)$ is

$$
M_{x}(t)=p \alpha \times \mathrm{B}(\alpha+t, 1-t)+(1-p) \beta \times \mathrm{B}(\beta-t, 1+t),
$$

for $\max \{-1, \alpha\}<t<\min \{1, \beta\}$.

From Result 3, by differentiation techniques, we obtain the mean and variance of the $\operatorname{LMD}(p, \alpha, \beta)$ as given in the following result.

Result: The mean and variance of $\operatorname{LMD}(p, \alpha, \beta)$ with PDF (7) are

$$
\begin{aligned}
& \text { Mean }=p \alpha \psi(\alpha)+1(1-p) \beta \psi(\beta)-(p \alpha+p \beta-\beta) \psi(1) \\
& \text { variance }=p \alpha\left[\psi^{\prime}(\alpha)+\psi^{\prime}(1)\right]+p \alpha(1-p \alpha)[\psi(\alpha)-\psi(1)]^{2}+ \\
& (1-p) \beta\left[\psi^{\prime}(\beta)+\psi^{\prime}(1)\right]+(1-p) \beta[1-(1-p) \beta][\psi(1)-\psi(\beta)]^{2}- \\
& 2 p(1-p) \alpha \beta[\psi(\alpha)-\psi(1)][\psi(1)-\psi(\beta)],
\end{aligned}
$$

\begin{tabular}{|c|c|c|c|c|}
\hline \multicolumn{5}{|c|}{ Distribution } \\
\hline & $L D(\mu, \sigma)$ & $L D_{I}(\mu, \sigma, \alpha)$ & $L D_{I I}(\mu, \sigma, \beta)$ & $\operatorname{LMD}(\mu, \sigma, p, \alpha, \beta)$ \\
\hline$\hat{\mu}$ & 112.858 & 110.657 & 110.874 & 109.461 \\
\hline$\hat{\sigma}$ & 5.26 & 5.691 & 4.804 & 5.781 \\
\hline$\hat{\alpha}$ & - & 1.28 & - & 1.713 \\
\hline$\hat{\beta}$ & - & - & 0.789 & 1.928 \\
\hline$\hat{p}$ & - & - & - & 0.879 \\
\hline AIC & 657.274 & 652.906 & 653.124 & 646.303 \\
\hline BIC & 657.153 & 655.352 & 655.57 & 650.381 \\
\hline CAIC & 659.153 & 658.352 & 658.57 & 655.381 \\
\hline HQIC & 654.424 & 649.603 & 649.821 & 640.798 \\
\hline
\end{tabular}

in which $\psi($.$) is the psi or digamma function.$

Table 1: Estimated values of the parameters with the corresponding information criterion values. 
On differentiating the PDF $f(x)$ of the $\operatorname{LMD}(p, \alpha, \beta)$ with respect to $\mathrm{x}$ and equating to zero, we obtain the following result, useful for the computation of the mode of the distribution.

Result: The mode of $\operatorname{LMD}(p, \alpha, \beta)$ with PDF (7) satisfies the following equation

$$
\frac{p \alpha}{(1-p) \beta^{2}}=\frac{\left(e^{-x}-\beta\right)\left(1+e^{-x}\right)^{\alpha-\beta}}{\left(\alpha e^{-x}-1\right)}
$$

Note that by using the mathematical softwares such as MATHCAD, MATHEMATICA, R we can easily evaluate the mean and variance.

\section{Application}

For illustrating the usefulness of the $\operatorname{LMD}(\mu, \sigma, p, \alpha, \beta)$ model, here we considered the IQ data set of 87 white males hired by an insurance company in 1971 taken from Roberts [14]. We obtain the maximum likelihood estimates (MLEs) of the parameters of the $\operatorname{LMD}(\mu, \sigma, p, \alpha, \beta)$ by using the MaxLik package in $\mathrm{R}$ software. The values of the Akaike information criterion (AIC), Bayesian information criterion (BIC), Consistent Akaike information criterion (CAIC) and Hannan Quinn information criterion (HQIC) are computed for comparing the model $\operatorname{LMD}(p, \alpha, \beta)$ with the existing models - $L D(\mu, \sigma)$, $L D_{I}(\mu, \sigma, \alpha)$, LMD $(\mu, \sigma, \beta)$. The results obtained are given in Table 1. From Table 1 it is seen that the AIC, BIC, CAIC and HQIC values are minimum for $L D_{I I}(\mu, \sigma, p, \alpha, \beta)$ compared to other models. Based on the computed values of the AIC, BIC, CAIC and HQIC one can observe that the LMD $(\mu, \sigma, p, \alpha, \beta)$ model gives better fit to the data set compared to $L D, L D_{I}$ and $L D_{I I}$.

\section{References}

1. Oliver FR (1982) Notes on the logistic curve for human population. Journal of the Royal Statistical Society Series A 145: 359-363.

2. Peal R, Reed L J (1924) Studies in Human Biology. Williams and Wilkins, Baltimore.

3. Pearl R, (1940) Medical Biometry and Statistics. Saunders, Philadelphia.

4. Emmens CW (1941) The dose-response relation for certain principles of the pituitary gland, and of the serum and urine of pregnancy. Journal of Endocrinology 2: 194-225.

5. Berkson J (1994) Application of the logistic function to bioassay. Journal of the American Statistical Association 37: 357-365.

6. Berkson J (1951) Why I prefer logits to probits. Biometrics 7: 327-339.

7. Finney DJ (1947) The principles of biological assay. Journal of the Royal Statistical Society, Series B, 9: 46-91.

8. Finney DJ (1952) Statisitcal methods in Biological Assay. Hafner, New York.

9. Plackett RL (1959) The analysis of life test data. Technometrics 1: 9-19.

10. Dyke GV, Patterson HD (1952) Analysis of factorial arrangements when the data are proportions. Biometrics 8: 1-12.

11. Fisk PR (1961) The graduation of income distributions. Econometrica 29: 171-185.

12. Balakrishnan N (1992) Handbook of Logistic Distribution, Dekker, NewYork.

13. Roberts HV (1988) Data Analysis for Managers with Minitab. Scientific Press, Redwoodcity, California, USA.

14. Balakrishnan N, Leung MY (1988) Order Statistics from the Type I Generalized logistic distribution. Communications in Statistics Simulation and Computation 17(1): 25-50.

\section{Your next submission with Juniper Publishers}

will reach you the below assets

- Quality Editorial service

- Swift Peer Review

- Reprints availability

- E-prints Service

- Manuscript Podcast for convenient understanding

- Global attainment for your research

- Manuscript accessibility in different formats

( Pdf, E-pub, Full Text, Audio)

- Unceasing customer service

Track the below URL for one-step submission https://juniperpublishers.com/online-submission.php 